\title{
Traditional Food Culture (Local Cuisines, Japanese Sake) That Has Been Nurtured by the Rich Nature of the Region: The Case of the Coastal Area in Chiba Prefecture, Japan
}

\author{
Korehisa Kaneko $^{1^{*}}$, Keiko Oshida ${ }^{2}$, Hajime Matsushima ${ }^{3}$ \\ ${ }^{1}$ Hokuso Creature Association, Tokyo, Japan; ${ }^{2}$ Department of Town Planning and Design, College of Science and Technology, Ni- \\ hon University, Chiba, Japan; ${ }^{3}$ Research Faculty of Agriculture, Hokkaido University, Sapporo, Japan. \\ Email: ${ }^{*}$ k_kaneko@hotmail.com \\ Received June $8^{\text {th }}, 2013$; revised July $8^{\text {th }}$, 2013; accepted July $15^{\text {th }}, 2013$ \\ Copyright (C 2013 Korehisa Kaneko et al. This is an open access article distributed under the Creative Commons Attribution License, \\ which permits unrestricted use, distribution, and reproduction in any medium, provided the original work is properly cited.
}

\begin{abstract}
In Chiba Prefecture, Japan, during the Edo period (1603-1867), the development of waterway traffic by ships and the management of ports, highways and post towns around the ports progressed with the prosperity of the Edo (present-day Tokyo), which became heavily populated and the center of politics. We estimated that the demand of Japanese sake, which is luxury grocery item, was high. The freshwater layer that is abundant in mineral water to a depth of approximately $10 \mathrm{~m}$ is formed in coastal sand dunes. The fresh water layer is hard water, in which the concentrations of minerals such as calcium and magnesium are high. When the fresh water layer is used as the preparation water, the working rice malt and yeast in the sake brewing process become active. Japanese sake trends to be dry with a full-bodied taste. In addition, the main ingredients of local cuisines are fish and shellfish; many local cuisines are seasoned using soy sauce, miso and salt, and these local cuisines pair well with the type of Japanese sake described above. The local cuisines have been nurtured in harmony with the region's rich nature and heritage. In the future, we need to conserve the rich natural environment of the tidal flat, coast, seaweed beds, and marine, which have been producing the main local cuisine in Chiba Prefecture, and the water source area (a successive environment on the plateau from the coast, which was previously called the coastal dune area) of the preparation water for making Japanese sake. We also need to proactively develop local production for local consumption activities. Thus, we hypothesize that if the Japanese food life is secured and the traditional food culture is continued, the region will become revitalized by the development of the exchanges in the region.
\end{abstract}

Keywords: Local Cuisines; Japanese Sake; Traditional Food Culture; Coastal Environment; Blessing of Nature

\section{Introduction}

Chiba Prefecture is located in the central portion of the Japanese archipelago and is surrounded by the sea on three sides by Tokyo Bay and the Pacific Ocean. On the Tokyo Bay side, the tidal flats and shallows were spread until the period of rapid economic growth (1950) after World War II, and the region on the Pacific Ocean side is blessed with nature, where the Kurosio (warm current) and Oyashio (cold current) are confluent and the seafood is rich. In particular, since Ieyasu Tokugawa opened sho-

${ }^{*}$ Corresponding author. gunate at Edo (present-day Tokyo) in 1603, Edo flourished as a central city of politics, economics and culture in Japan and became the major food consumption area with the rapid increase in population. In Chiba Prefecture, which is located close to Edo, large-scale development of rice paddies was conducted to increase rice production. Moreover, fishing and fishing villages have developed significantly with the rapid increase in migrant fishing populations from the southwestern region in Japan, which developed the fishery regions at the time, and fishing technology progressed. Consequently, a new settlement was created, and the population of Chiba Prefec- 
ture increased [1]. Through ties with the capital of Edo, land and water transportation routes in Chiba Prefecture developed, and post towns, ports, and the highway developed. [2] reported that during the Edo period, Japanese sake was actively made, and in the coastal and rural regions in Chiba Prefecture, high quantities of Japanese sake were consumed. In particular, there are many towns where the function of the port was developed [3]; the coastal sand dune zone near the port formed a layer of fresh water approximately $10 \mathrm{~m}$ underground originating from rain filtered through the sand stratum and the land area. The fresh water layer is hard water, in which the concentrations of minerals such as calcium and magnesium are high; hard water activates rice-malt and yeast, making the fresh water suitable for sake brewing $[4,5]$. We suggested that the demand of Japanese sake, which is luxury grocery item, was high. This origin of local cuisines is unknown; however, it is known that fishermen had to eat on the ship. As inferred from the history and culture, the main local cuisine in Chiba Prefecture contains many fish dishes [6]. The local cuisine was used as a relish and has evolved as a traditional food culture and in the regional industry. The relationship between nature and traditional food culture is very important to support the foundation population survival. However, few examples of this relationship have been examined in detail, which is an issue to be considered.

In this study, we report the relationship between nature and traditional food culture (including local cuisines and Japanese sake).

\section{Materials and Methods}

\section{Study Site}

Chiba Prefecture is located in the central portion of the Japanese archipelago and is surrounded by the sea on three sides by Tokyo Bay and the Pacific Ocean (Figure 1). On the Pacific Ocean side, where the Kurosio (warm current) and Oyashio (cold current) are confluent, there are rich fishing grounds that the environment has varied. Fisheries are one of the largest industries in the country that focuses on coastal fishing and offshore fishing. Based on fishing methods, such as unloaded fish and topographical features of the coast, the area was divided into 4 areas as follows: Choshi-Kjuukuri (Choshi City to Ichinomiya City: coastline extension $83.1 \mathrm{~km}$ ), Sotobo (Isumi City to Minami-Boso City: coastline extension 132.7 km), Uchibo (Tateyama City to Futthu City: coastline extension $85.0 \mathrm{~km}$ ), and Inner Bay of Tokyo Bay (Kisarazu City to Urayashu City: coastline extension $197.0 \mathrm{~km}$ ) [3]. For sea fishery catches in 2012, Chiba was ranked 7th in Japan with 162,634 tons [7].



Figure 1. Study sites.

\section{Results}

\subsection{The Main Local Cuisines in Chiba Prefecture}

The main local cuisines in Chiba Prefecture are mainly fish dishes such as a mactra chinensis dish, a sardine dish, gomazuke, kusari-zushi (sushi seasoned with vinegared fish), sliced raw fish, sanga broil, namerou (cuisine chopped with miso and spice fresh fish), finely chopped horse mackerel, a bonito dish, a conger eel dish, turbo cooked in its own shell, and a saury dish, among others [8].

The Choshi-Kujuukuri region is the producing area of local cuisine, such as the sardine dish and the saury dish; the Kujuukuri, Sotobo, and Uchibo areas produce the finely chopped horse mackerel, bonito dish, turbo cooked in its own shell, nuta of turban shell, and magocha. The Sotobo and Uchibo areas produce namerou and sanga broil, and the Inner Bay of Tokyo Bay produces the conger eel dish, manila clam dish, and the mactra chinensis dish (Table 1).

As a taste of local cuisine, the mactra chinensis dish and the sardine dish (sliced raw sardine, finely chopped horse sardine) are mainly slightly plain in taste; the sanga broil, finely chopped horse mackerel, and bonito dish are either slightly or heavily seasoned using soy sauce, miso, vinegar, or other flavorings. The conger eel dish, Namero, and turbo cooked in its own shell are heavily seasoned to taste using salt, soy sauce, and secret sauce.

\subsection{The Catch of Major Fish and Shellfish That Are Ingredients of Local Cuisine}

We investigated the catch of the main fish and shellfish 
that are ingredients of local cuisine in each area [9-12] with respect to the composition rate of the catch in each area. Sardines and saury accounted for approximately $85 \%$ of the whole catch in the Choshi-Kujukuri area. Tunas and pompanos were plentiful in the Choshi-Kujukuri and Sotobo areas; the total catch in these areas was more than $80 \%$. Bonitos and turban shell were high at $50 \%$ to $80 \%$ of the total catch in the Sotobo area. Conger and little necks were the highest in the Inner Bay of Tokyo Bay and Uchibo; they were more than $80 \%$ of the total catch (Table 2, Figure 2).

Regarding changes in the average catch of fish and

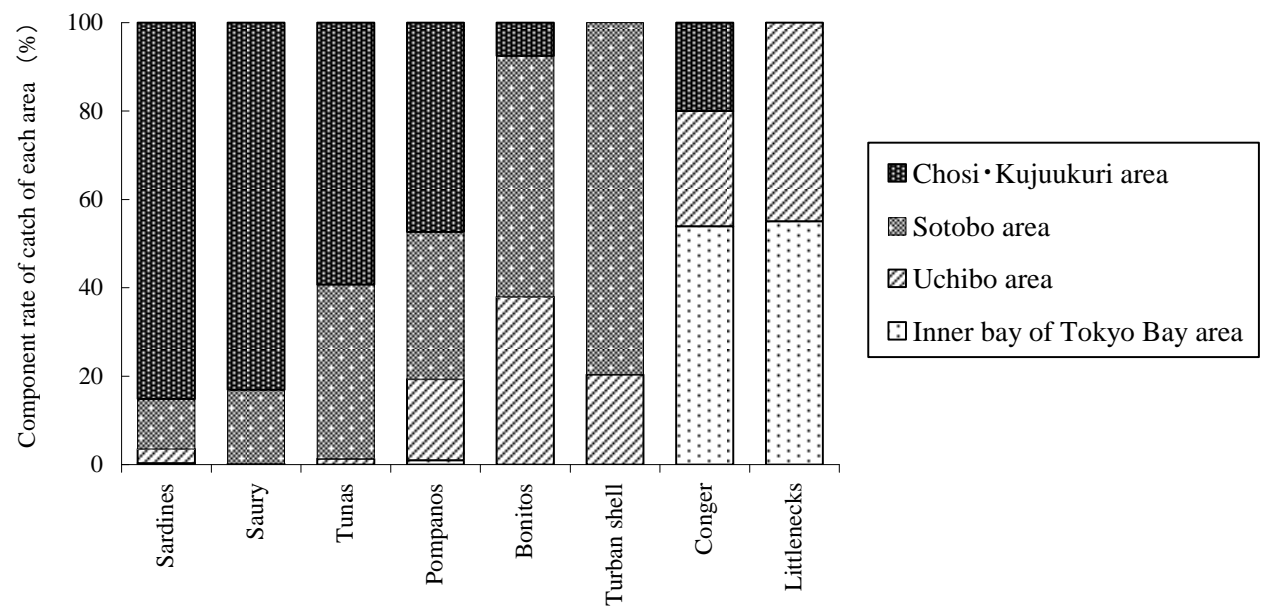

The main fish and shellfish used local cuisine

Figure 2. The composition rate of catch in each area of Chiba Prefecture. ※ Data quoted from Ministry of Agriculture, Forestry and Fisheries (2012), and Agriculture, Forestry and Fisheries statistics annual report (2010-2011).

Table 1. The main local cuisine in Chiba Prefecture.

\begin{tabular}{|c|c|c|c|}
\hline Area division & Dish name & Food ingredients & Dish summary \\
\hline \multirow{2}{*}{ Choshi·Kujuukuri } & Sardine dish & Sadine, Anchovy, etc. & $\begin{array}{l}\text { Sardine dish is counted more than } 100 \text { kinds as sliced } \\
\text { row fish, chopped fish, sesame pickle etc. }\end{array}$ \\
\hline & Saury dish & Saury & Grilled with salt, sliced row fish, etc. \\
\hline \multirow{5}{*}{ Kujuukuri·Sotobo·Uchibo } & $\begin{array}{l}\text { Finely chopped horse } \\
\text { mackerel }\end{array}$ & Horse mackerel & Cooking picked to vinegar Namerou. \\
\hline & Turbo cooked in its own shell & Turban shell & $\begin{array}{l}\text { This dish roast fire directly turban shell, season with } \\
\text { soy source, and eat out after backed. The origin is } \\
\text { unknown, but had appeared in the (1603-1867) } \\
\text { Edo period. }\end{array}$ \\
\hline & Nuto of turbon choll & Turbon shollt & $\begin{array}{l}\text { Cooking mixed with mustard vinegared miso and } \\
\text { vinegared miso the turban shell. }\end{array}$ \\
\hline & Nuta or turban snell & rurban sneIl & $\begin{array}{l}\text { Nuta means that reminds a marsh and field because } \\
\text { miso source is semi-solid. }\end{array}$ \\
\hline & Magocha & Tunas·Bonitos & Chazuke using tunas and bonitos pickled soy souce. \\
\hline \multirow[t]{2}{*}{ Sotobo·Uchibo } & Namerou & $\begin{array}{l}\text { Horse mackerel, sardine, saury, } \\
\text { mactra chinensis, etc. }\end{array}$ & $\begin{array}{l}\text { Cooking mixed with miso, ginger, chopped leeks and } \\
\text { green perilla after chopped fish found in coastal waters } \\
\text { of Sadine and hoese mackerel, etc. Raw fish dish that } \\
\text { can be eaten without the soy sauce. }\end{array}$ \\
\hline & Sanga boil & $\begin{array}{l}\text { Horse mackerel, sardine, saury, } \\
\text { mactra chinensis, etc. }\end{array}$ & $\begin{array}{l}\text { Cooking method was molded into a hamburger shape } \\
\text { knead well Namero, and baked it. }\end{array}$ \\
\hline \multirow{3}{*}{ Inner Bay of Tokyo Bay } & Conger eel dish & Conger & Conger eel rice, Teppou boiled of conger eel etc. \\
\hline & Manila clam dish & Manila clam & Manila clam rice, Manila clam spits etc. \\
\hline & Mactra chinensis dish & Mactra chinensis & Sliced row fish, Tempura, Vinegared food. \\
\hline
\end{tabular}

※ Data quoted the hundred best local cuisines (Chiba Prefecture): http://www.rdpc.or.jp/kyoudoryouri100/ryouri/12.html 
Table 2. The catch of each municipalities of the main fish and shellfish using local cuisine in Chiba Prefecture (2009).

\begin{tabular}{|c|c|c|c|c|c|c|c|c|c|}
\hline \multirow{2}{*}{ Area division } & \multirow{2}{*}{ Municipalities } & \multicolumn{8}{|c|}{ Fish and sellfish } \\
\hline & & Sardines & Saury & Tunas & Pompanos & Bonitos & Turban shell & Conger & little necks \\
\hline \multirow{10}{*}{ Chosi-Kujuukuri } & Chosi City & 21,176 & 15,098 & 358 & 284 & 93 & - & 22 & - \\
\hline & Asahi City & 37,004 & - & - & 483 & - & - & 0 & - \\
\hline & Sousa City & 22,184 & - & - & 306 & - & - & 0 & - \\
\hline & Yokoshibahikari Town & 0 & - & - & 0 & - & - & 0 & - \\
\hline & Sanmu City & 0 & - & - & 0 & - & - & 1 & - \\
\hline & Kujuukuri Town & 0 & - & - & 406 & - & - & - & - \\
\hline & Oamishirasato Town & 0 & - & - & 0 & - & - & - & - \\
\hline & Shirako Town & 6018 & - & - & 172 & 6 & - & - & - \\
\hline & Chosei Village & 2 & - & - & 4 & - & - & - & - \\
\hline & Ichinomiya Town & 1 & - & - & 22 & - & - & - & - \\
\hline \multirow{5}{*}{ Sotobo } & Isumi City & 2909 & - & - & 76 & 0 & 2 & 0 & - \\
\hline & Onjuku Town & 0 & - & 9 & 0 & 221 & 1 & - & - \\
\hline & Katsuura City & 0 & 265 & 118 & 6 & 264 & 74 & - & - \\
\hline & Kamogawa City & 6997 & 193 & 91 & 412 & 128 & 86 & - & - \\
\hline & Minamiboso City & 1596 & 2590 & 20 & 688 & 108 & 87 & 0 & - \\
\hline \multirow{3}{*}{ Uchibo } & Tateyama City & 1100 & 4 & 4 & 308 & 196 & 26 & 2 & - \\
\hline & Kyonan Town & 1770 & 26 & 4 & 231 & 306 & 27 & 1 & - \\
\hline & Futtsu City & 381 & 1 & - & 110 & 0 & 11 & 27 & 165 \\
\hline \multirow{6}{*}{ Inner Bay of Tokyo Bay } & Kisarazu City & 0 & - & - & 6 & - & - & 62 & 155 \\
\hline & Sodegaura City & 0 & - & - & 0 & - & - & - & $\mathrm{X}$ \\
\hline & Narashino City & 0 & - & - & 0 & - & - & - & 4 \\
\hline & Funabashi City & 357 & - & - & 30 & - & - & 0 & 27 \\
\hline & Ichikawa City & 0 & - & - & 0 & - & - & - & 16 \\
\hline & Urayasu City & 0 & - & - & 0 & - & - & 0 & $\mathrm{X}$ \\
\hline
\end{tabular}

shellfish from 1960 to 2009, tunas, saury, littlenecks, and conger were markedly decreased. Sardines and turban shell were at their highest of 1980 to 1989; these fish have decreased since 1989. Bonitos were increasing and decreasing by the period; however, during the period of 2000 to 2009, the fish decreased compared with that of 1990 to 1999. Pompanos was the highest in the period of 1990 to 1999; however, they decreased in the period of 2000 to 2009 (Figure 3).

\subsection{Sake Breweries in Chiba Prefecture}

The oldest sake brewery in Chiba Prefecture was established in the early Edo period, and many sake breweries established in the Meiji period. Notably, the opening of the brewery was free during the early Meiji period, and the number of sake breweries was 800 in 1879 and was more than 1000 in 1883. However, with the ban of home brewed sake in 1896, the number of sake breweries decreased to approximately 200 by the end of the Meiji period. Since then, the number of sake breweries has decreased by half because of a large tax increase on liquor for the expenses of war, particularly the maintenance of enterprises during the Second World War [13]. With the impact of the reduced demand for Japanese sake after the Second World War, the number of sake breweries in Chiba Prefecture is currently 39 (December 2012). The 39 breweries included home brewing, which has not been 

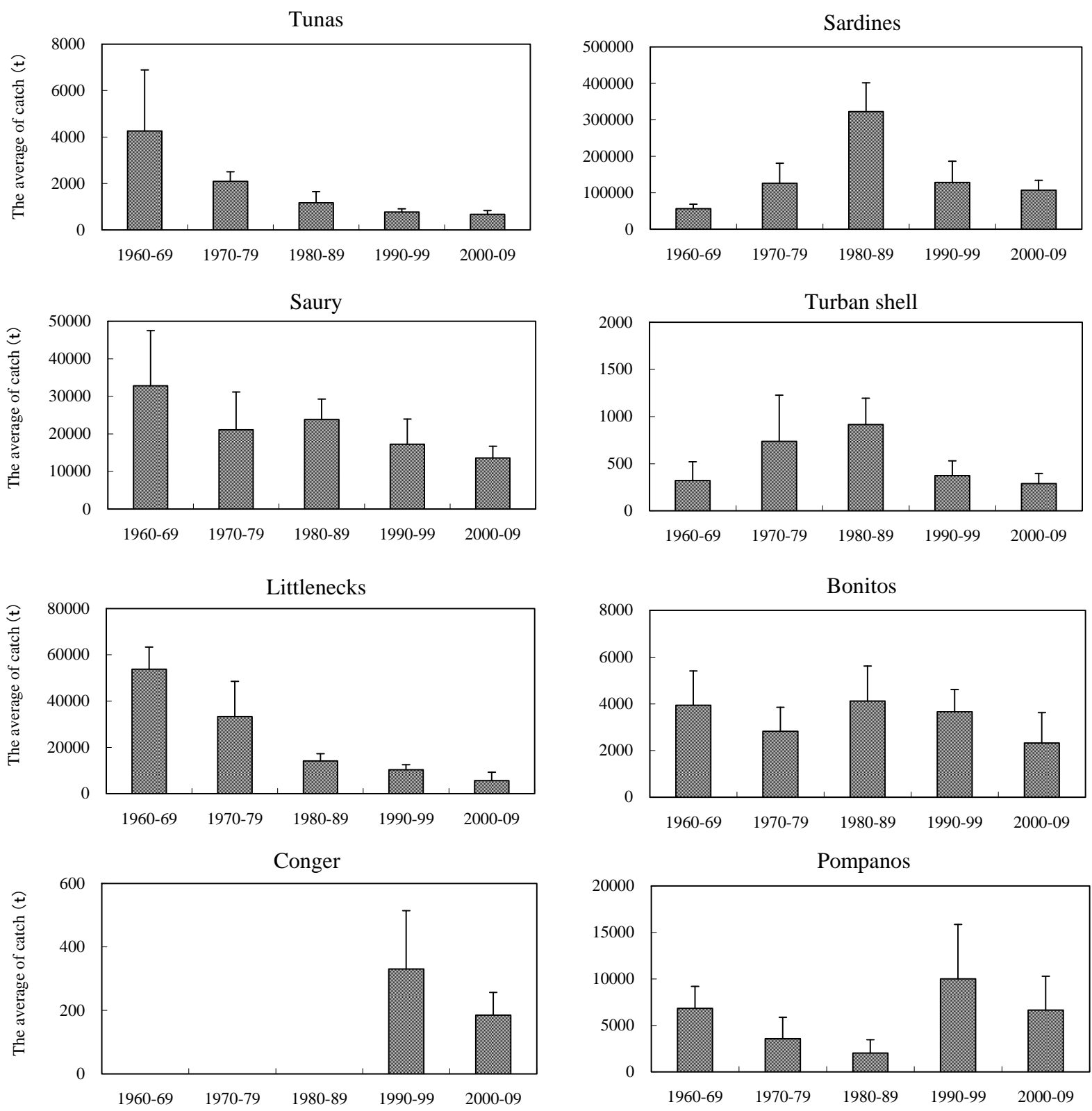

Figure 3. The change in the average catch of fish and shellfish that is used in the main local cuisine in Chiba (1960-2009). *Data quoted from Chiba Prefecture, Agriculture, Forestry and Fisheries Division, fisheries station (2012). ${ }^{*}$ Data quoted from Ministry of Agriculture, Forestry and Fisheries, Kanto Regional Agricultural Administration Office, Agricultural administration office Chiba Department of Statistics (2007-2009).

conducted for several decades. There is an environmental distinction of sake breweries in Chiba Prefecture; there are 16 sake breweries in the plateau/mountainous region, 13 in the river plains, and 10 in the coastal vicinity [4,5].

\subsection{Affinity with Japanese Sake and Local Cuisines}

Based on an article from [14], we researched the relationship between tastes of the main local cuisines and the Japanese sake that is made in their production areas. The slightly plain taste of the mactra chinensis dish and the sardine dish matched the Japanese sake of the taste that is slightly crispy and dry; the fatty meat and slightly heavytasting cooking of sanga broil, kusari-zushi, finely chopped horse mackerel, and the bonito dish matched the Japanese sake of a slightly deep taste that is dry and mellow. The heavy-tasting cooking of the namerou, the conger eel dish, turbo cooked in its own shell, and the saury dish matched the Japanese sake of deep taste that is slightly dry and deep (Figure 4). Moreover, the prepara- 
tion water of the sake brewery that is located in the production areas of the above-mentioned local cuisines had an average hardness of $15 \mathrm{dh}$, which is considered to be very hard water by the World Health Organization rankings (Figure 5).

We investigated the relationship between the sake meter value and acidity with the Japanese liquor Junmaishu (sake made without added alcohol or sugar) of each sake brewery in the coastal area of Chiba Prefecture (In the liquor tax law of the United States, because sake without added alcohol is brewed as Japanese sake, it has selected the above types). The sake meter value was $2.86 \pm 0.73$, and the acidity was $1.61 \pm 0.12$, and these values were the taste of deep and dry (Figure 6).

- Sake meter value: The value is a measure to represent the dryness and sweetness of Japanese sake. When the sugar content is higher, the specific gravity becomes heavy. When measured using a sake meter, the value of water is 0 . When the sake meter value is negative, it indicates a sweet taste and that the specific gravity of the sake is heavier than that of water.

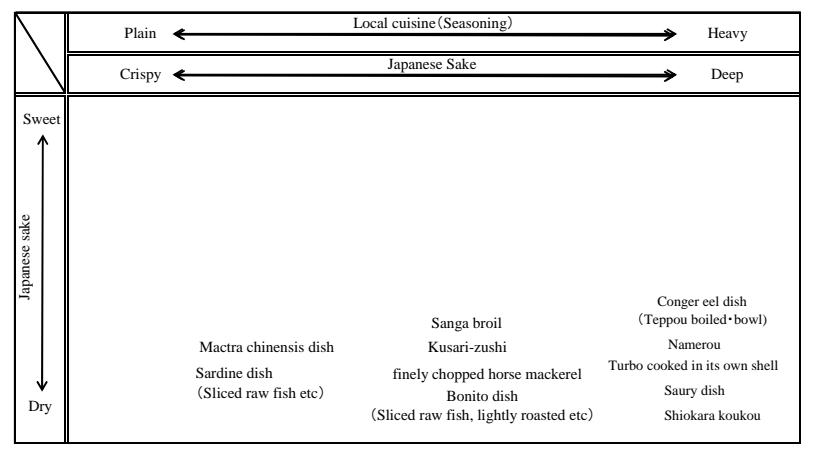

Figure 4. Taste of Japanese sake compared to the seasoning of the main local cuisine in Chiba Prefecture. ${ }^{*}$ Data quoted Food and Beverage Specialist Organization (NPO) (2009).

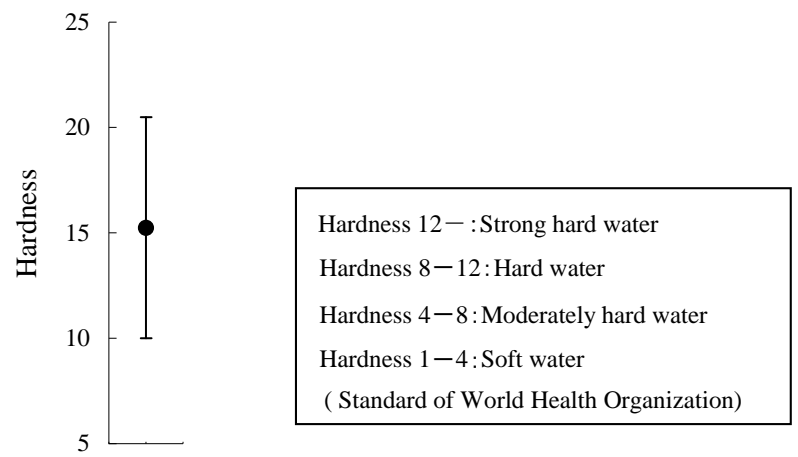

Figure 5 The average hardness of the preparation water of the sake brewery that is located in the coastal zone in Chiba Prefecture. ${ }^{*}$ indicate the average value. The vertical bars indicate the standard deviation.

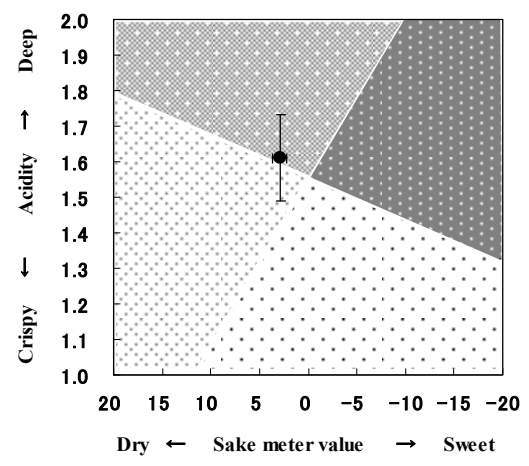

Deep and dry: Acidity and sugar content are many, the flavor is richness and sharpness. Deep and sweet: Acidity and sugar content are many, the flavor is richness and mellowness. Crispy and dry: Acidity and sugar are less, the flavor is sharpness and refreshing.

Crispy and sweet: Acidity and sugar content are less, the flavor is mellowness and refreshing.

Figure 6. The relationship between the sake meter value and the acidity of the sake brewery (Junmai course) in the coastal area of Chiba Prefecture. ${ }^{*}$ In the Liquor Tax Law of the United States, sake that is not Junmai course is not considered a brew of Japanese sake. ${ }^{*}$ Junmai course: Sake made without added alcohol or sugar

When the sake meter value is positive, it indicates a dry taste and that the specific gravity of the sake is lighter than that of water.

- Acidity: The value representing the amount of acid contained in the Japanese sake. Japanese sake of high acidity tastes dry and deep, and that of low acidity tastes sweet and crispy.

\section{Discussion}

In the local cuisine of Chiba Prefecture, many dishes use fish and shellfish ingredients; these dishes have been eaten by fishermen on ships and in the port. We hypothesized that the development of fishery and the marine products industry since the Edo periods has greatly influenced the local food culture. The Choshi-Kujuukuri areas produces the sardine dish and the saury dish, the Kujuukuri, Sotobo, and Uchibo areas produce the finely chopped horse mackerel, bonito dish, turbo cooked in its own shell, nuta of turban shell, and magocha. The Sotobo and Uchibo areas produce namerou and sanga broil, and the Inner Bay of Tokyo Bay produces the conger eel dish, manila clam dish, and the mactra chinensis dish (Table 1). The catch of the fish and shellfish that are the ingredients of the local cuisines was high in relation to the producing area (Table 2). We found that the blessings of nature in each area affect the food culture. Currently, the number of sake breweries near the coast of Chiba Prefecture is 10 (February 2012), while the number of sake breweries in 1925 was three times that [13]. We estimated that the demand for Japanese sake was high in the city, which was influenced by the development of the 
port function, land and water transportation line.

The similarity in taste between local cuisine and Japanese sake that was brewed in the vicinity of the producing area was analyzed. The slightly bland taste of the mactra chinensis dish and sardine dish match the Japanese sake taste, which is slightly crispy and dry. When the seasoning of the dish becomes heavier, the trend was to pair the food with a Japanese sake of a full-bodied and dry taste, which is deep and delicious (Figure 4). Moreover, the preparation water of the sake brewery that is located in the producing area of the above local cuisines was found to be very hard water based on the World Health Organization rankings (Figure 5). The hardness of the preparation water in Chiba Prefecture was high in the coastal areas of the alluvium region and was low in the inland side of the diluvium region [4,5]. The very hard water becomes the nutrient source for yeast and invigorates the fermentation. Japanese sake that is brewed using hard water easily becomes full-bodied, deep and dry. Japanese sake that is brewed using soft water easily has a mellow taste and is slightly sweet [13]. We evaluated the sake based on the sake meter value and the acidity of sake (Japanese liquor junmaishu) made without added alcohol or sugar that was brewed in the sake brewery located in the coastal dunes. The Japanese sake from that sake brewery had a deep and dry taste (Figure 6). [14] reported that a full-bodied and dry Japanese sake that is brewed with hard water tends to match with a heavily seasoned local cuisine. Moreover, [15] reported that amino acid and inosinic acid containing fish and shellfish are suitable with succinic acid, which is the component that provides the sake's deep taste. In Japanese sake that is brewed in the coastal area and contains high succinic acid, we consider that Japanese sakes in these regions have been brewed to match the delicious taste of fish and shellfish.

Consequently, we consider that local cuisine using fish and shellfish ingredients and the Japanese sake that is brewed with water from the fresh water layer under the coastal dune are of a high value as a traditional food culture, which has developed the local production and consumption, and has composed in coexistence with people and a rich natural environment for many years. However, regarding changes in the average catch from 1960 to 2009, all fish and shellfish during 2000-2009 mostly decreased compared with the peak catch period. In particular, tunas were $6 \%$ of the peak catch period; saury, turban shell and littlenecks were approximately $20 \%$ of the peak catch period, and sardines and congers were 34\% - 39\% of the peak catch period (Figure 3).

In the future, if excessive harvesting of fish and shellfish, water pollution and environmental destruction progress and these habitats deteriorate, we predict that the catch will be further decreased, which means that the local cuisine could potentially disappear. Moreover, since the Edo period, large-scale development of farmland has been conducted mainly in the plain areas. In recent years, the conversion to residential land from farmland in the plain areas, the construction of industrial parks and land-scale multi-unit apartments on the plateau has increased [3]. We suggest that these actions exacerbated the water quality of the fresh water layer in the basement of the coastal dunes and would adversely affect the taste of Japanese sake.

On this subject, it is necessary to conserve the rich natural environment in the tidal flats, coast, sea grass beds, and sea that produce the local cuisines of Chiba Prefecture, the water source (a successive environment on the plateau from coast to plateau that was previously called the coastal sand dune area) of the preparation water for making Japanese sake that matches the local cuisines, and the activities of aggressive local production for local consumption. Thus, we believe that if the Japanese food culture is safe and secure, the traditional food culture will continue, and it would be able to promote regional revitalization through the development of the exchanges in the region.

\section{Acknowledgements}

We wish to sincerely express our gratitude to the people in the sake breweries in Chiba Prefecture, Japan, who provided information.

\section{REFERENCES}

[1] Chiba Prefecture, Planning Department, Citizen Section, "Chiba Prefectural History (Meiji Edition Offprint)," Chiba Prefecture, Chiba, 1962.

[2] N. Takahashi, "Sake of Boso in Edo Period-To Sales and Consumption from Manufacturing,” Material for Prefectural History Lecture in Chiba, Prefectural Archives, 2012.

[3] Chiba Historical Materials Study Foundation, "Chiba Prefectural History, Distinction, Geographical Book 1, General Remarks, Prefectural History Series 36,” Chiba Prefecture, Gyosei, 1996.

[4] K. Kaneko, K. Oshida and H. Mathushima, "Ecosystem Services on Coastal Sand Beach, the Significance as Provisioning, Regulating, Cultural Services,” Japanese Journal of Landscape Ecology, Vol. 17, No. 1, 2012, pp. 1924.

[5] K. Kaneko, K. Oshida and H. Mathushima, "Ecosystem Services of Coastal Sand Dunes Saw from the Aspect of Sake Breweries in Chiba Prefecture, Japan: A Comparison of Coastal and Inland Areas," Open Journal of Ecology, Vol. 3, No. 1, 2013, pp. 48-52.

doi:10.4236/oje.2013.31006 
[6] U. Naruse, “47 Administrative Divisions of Japan-Traditional Food Encyclopaedia,” In: U. Naruse, Ed., Part II Administrative Divisions-Traditional Food and Characteristics, Maruzen Co., Ltd., Tokyo, 2009, pp. 102-107.

[7] Chiba Prefecture, Agriculture, Forestry and Fisheries Division, Fisheries Station, "Chiba Fisheries Handbook (Web Edition),” Chiba Prefecture, Chiba, 2012.

[8] Rural Development Planning Commission, "The Hundred Best Local Cuisines, Chiba Prefecture,” 2007. http://www.rdpc.or.jp/kyoudoryouri100/ryouri/12.html

[9] Ministry of Agriculture, Forestry and Fisheries, “Agriculture, Forestry and Fisheries Statistics Annual Report (2012-2013),” Department of Fisheries, Kanto Regional Agricultural Administration Office Department of Statistics, Tokyo, 2012, pp. 216-259.

[10] Ministry of Agriculture, Forestry and Fisheries, "Agriculture, Forestry and Fisheries statistics. 2006 Sea Fishery Fishery Statictics (Chiba Prefecture-Rough Number)," Kanto Regional Agricultural Administration Office, Agricultural Administration Office Chiba Department of Statistics, Chiba, 2007, pp. 1-6.

[11] Ministry of Agriculture, Forestry and Fisheries, "Agriculture, Forestry and Fisheries Statistics. 2007 Sea Fish- ery Fishery Statictics (Chiba Prefecture-Rough Number)," Kanto Regional Agricultural Administration Office, Agricultural administration office Chiba Department of Statistics, Chiba, 2008, pp. 1-9.

[12] Ministry of Agriculture, Forestry and Fisheries, "Agriculture, Forestry and Fisheries Statistics, 2008 Sea Fishery Fishery Statictics (Chiba Prefecture-Rough Number)," Kanto Regional Agricultural Administration Office, Agricultural administration office Chiba Department of Statistics, Chiba, 2009, pp. 1-6.

[13] K. Suzuki, "Sake History of Chiba-Sake Brewing-A Heart and Climate and the History," Chiba Brewing Association, Chiba, 1997.

[14] Food and Beverage Specialist Organization, "Motoi of Japanese Sake-To You Who Aims at the Professional, Japanese Sake Sommelier of Japanese Sake, Lecture Text,” Sake Service Institute, Tokyo, 2009.

[15] U. Naruse, "Science of Sake and Relish,” In: U. Naruse, Ed., Delicious Sake and Relish, 4th Section, First Chapter, Relish Agree with Japanese Sake, Science I Shinsho, Tokyo, 2009, pp. 67-85. 